\title{
25 Research Soure \\ The role of inflammatory cytokines in dry eye in type 2 diabetic patients
}

\author{
Hong Cui \\ Yanbian University Hospital \\ Zheng-ri Li \\ Yanbian University Hospital \\ Ning Ren \\ Yanbian University Hospital \\ Li-xia Sun \\ Yanbian University Hospital \\ Ying-jun Li ( $\square$ liyingjun1301@163.com ) \\ Yanbian University Hospital
}

\section{Research article}

Keywords: Inflammatory cytokines; Diabetes mellitus; Dry eye;

Posted Date: February 26th, 2019

DOI: https://doi.org/10.21203/rs.2.412/v1

License: (c) (i) This work is licensed under a Creative Commons Attribution 4.0 International License.

Read Full License 


\section{Abstract}

Background The aim of this study was to explore the relationship between the ocular surface characteristics and the levels of tear and conjunctiva inflammatory cytokines. Methods This study enrolled 102 diabetes patients with dry eye (DE) and 117 volunteers. All enrolled subjects were tested in the following sequence: Ocular surface disease index (OSDI) was self-answered and ocular surface characteristics including Schirmer I test (SIt), tear-film breakup time (BUT), and corneal fluorecein staining (CFS) were evaluated. Levels of transforming growth factor (TGF)- $\beta 1$, nuclear factor-KB (NF-KB), and interleukin-17 (IL-17) were measured in the conjunctiva using a multiplex immunobead assay. Periodicacid-Schiff (PAS) staining, immunohistochemistry, enzyme-linked immunosorbent assay (ELISA) and flow cytometry were also performed. Spearman correlations between cytokines and ocular surface parameters were calculate. Results The ELISA results showed that the levels of IL-I $\beta$ and TNF- $\alpha$ in the DE patients with diabetes group were significantly higher than those in the normal group $(\mathrm{P}<0.001$ and $\mathrm{P}=$ 0.023). The immunohistochemical staining results and western-blot results showed that the expression levels of TGF- $\beta 1$ and NF-KB in the conjunctiva in the diabetes mellitus group were significantly increased compared to those in the normal group. The flow cytometric results showed that the expression levels of CCR6 and IL-17 were significantly increased in diabetes mellitus group compared to the normal group ( $P$ $<0.001$ and $\mathrm{P}<0.001$ ). Conclusions Inflammatory cytokines were highly expressed in the conjunctiva and tears of diabetic patients with dry eye. The mechanism for this might be related to hyperglycemiainduced activation of the NF-KB pathway, which increased the levels of inflammatory cytokines. In addition, chemokines might also play a role in the pathogenesis of dry eye in diabetes mellitus.

\section{Background}

Diabetes mellitus (DM) can cause many ocular complications such as keratoconjunctivitis, retinopathy, dry eye disease (DED), cataract, nerve palsies, glaucoma and macular edema. In recent years, in addition to diabetic retinopathy has received widespread attention for its role in causing blindness, the dry eye problem also has generated attention for its high incidence in diabetics $[1,2]$. Studies have shown that diabetics are susceptible to DED[3]. The occurrence of DED in diabetics is characterized by unstable tear production and tear volume, squamous metaplasia of the conjunctiva, a decrease in goblet cells density, a decrease in the hydrophilicity and stability of tear film, and the accumulation of inflammatory cytokines, in which the ocular surface is continuously damaged[4]. It is generally recognized[5] that the inflammation plays a prominent role in the pathogenesis of DED; However, there has been a lack of study on the pathogenesis of DED in diabetics. In this study, we investigated the levels of nuclear factor-KB (NF$\mathrm{KB})$, transforming growth factor- $\beta 1$ (TGF- $\beta 1$ ), interleukin-I $\beta$ (IL-I $\beta$ ), tumor necrosis factor- $\alpha$ (TNF- $\alpha$ ) and chemokines in the tears and conjunctiva of diabetics with DED and compared the results of this group with the results of the normal controls. We showed that the expression of the above mentioned inflammatory cytokines were significantly increased in the diabetic group compared to the normal control group. 


\section{Methods}

\section{Patients}

We studied 102 eyes from 102 diabetics, who were complicated with dry eye and had more than an 8-year history of diabetes, seen at the Department of Ophthalmology, Affiliated Hospital of Yanbian University, from January 2018 through April 2018, and 117 eyes from 117 healthy control individuals. The DM group (54 women and 48 men; mean age: $52.03 \pm 8.26$ years; age range: $42-73$ years) all met the diagnostic criteria for diabetes and diagnostic criteria for dry eye disease. The normal control group (60 women and 57 men; mean age: $55.12 \pm 6.31$ years; range: $40-69$ years) had non-DM and non-DED. There was no significant difference in gender and age composition between the DM group and normal group ( $P=$ $0.078, P=0.066$ ). The institutional review board at Affiliated Hospital of Yanbian University approved this study, which followed the tenets of the Declaration of Helsinki. Written informed consent was obtained from all patients after the nature and possible consequences of the study were explained.

The inclusion criteria and exclusion criteria for the normal group are based on the following. Inclusion criteria: no ocular irritation, no history of eye medication, Schirmer test (SIt) $>10 \mathrm{~mm} / 5 \mathrm{~min}$, tear film breakup time (BUT) $>10 \mathrm{~s}$, and no corneal fluorecein staining (CFS). Exclusion criteria: individuals who had an active ocular infection or inflammation, drug toxicity, contact lens wearing, ocular allergy, ocular surgery, and lid or lash abnormalities. Additionally, those with any ocular or systemic disease were excluded from this study.

The inclusion criteria and exclusion criteria for the DM group were based on the following : Inclusion criteria: 1. The diagnosis of diabetes was based on the criteria proposed by the 2014 American Diabetes Association (ADA) and included the following: (1) glycosylated hemoglobin ( $\mathrm{HbA1c}) \geq 6.5 \%$, (2) fasting plasma glucose (FPG) $\geq 7.0 \mathrm{mmol} / \mathrm{L}$, (3) two hours postprandial blood glucose ( $2 \mathrm{hPG}$ ) in oral glucose tolerance test $(\mathrm{OGTT}) \geq 11.1 \mathrm{mmol} / \mathrm{L}$, and (4) blood glucose of patients with typical hyperglycemia or hyperglycemia crisis were randomly detected $\geq 11.1 \mathrm{mmol} / \mathrm{L}$. 2 . A history of diabetes longer than 8 years. 3. The diagnosis of dry eye was based on the criteria included the following: (1) subjective symptoms: dryness sensation, foreign body sensation, burning sensation, red eye, many secretions, heavy sensation of the eyelids, visual fatigue, photophobia, lachrymation, itching sensation, eye pain, visual acuity fluctuation/ one or more of the first 6 symptoms needed to occur or persist on a regular basis, (2) BUT $\leq$ $5 \mathrm{~s}(++)$ or $\leq 10 \mathrm{~s}(+)$, (3) Sit $\leq 5 \mathrm{~mm} / 5 \mathrm{~min} \mathrm{(++)} \mathrm{or} \leq 10 \mathrm{~mm} / 5 \mathrm{~min}(+)$, and (4) CFS score $\geq 1$. According to the above mentioned criteria, the patients subjective symptoms and positive findings of DED on ocular examination (1 strong positive finding or 2 positive findings) were diagnosed as having DED. Exclusion criteria: The DM group included patients who had no ocular diseases and systemic diseases affecting tear secretion other than dry eye disease and diabetes.

\section{BUT}

Sodium fluorescein filter paper was used to touch the lower eyelid conjunctival sac of the tested subjects. The time, in seconds, between the last complete blink and the appearance of the first corneal black spot 
was measured and recorded.

\section{CFS}

After the tear film rupture test was performed, corneal epithelium staining was observed, and the staining area was graded on anumerical scale of $0-3$, with 0 representing no staining; 1 , scattered in dot staining or less than 5 staining points; 3 , high density spot or flake staining or massive or filamentous staining; 2 , between 1 and 3 . The score ranges from 0 to 12 .

\section{SIt}

A standard Schirmer test strip was placed in the lateral canthus with the eyes closed for an additional 5 min. The test paper was taken out, and the length of wetting of the strip was measured using a millimeter scale. The intensity of its staining was compared with that of a color standard.

\section{Dry eye symptom}

All subjects finished completing the dry eye symptom questionnaire (Ocular Surface Disease Index, OSDI), which was created by the International Dry Eye Workshop, under guidance of the same researcher. There were 12 problems, with a score of 0 100, 0 12 representing no symptoms, 13 32 moderate symptoms, and 33 100 severe symptoms.

\section{Conjunctival impression cytology}

A piece of $6 \mathrm{~mm}$ nitrocellulose filter (Mil-lipore) was applied tightly to the upper palpebral conjunctiva of the subject for approximately $5 \mathrm{~s}$. Then, it was removed from the conjunctiva and attached to $5 \times 5 \mathrm{~mm}$ size slides. The expression levels of NF-KB and TGF- $\beta 1$ in the conjunctiva were observed by periodic acidSchiff staining (PAS) and immunohistochemical staining.

\section{Tear collection}

Basal tear samples were collected atraumatically from the inferior tear meniscus of subjects using glass capillary tubes (Corning, New York, NY) or micropipettes (Eppendorf, Hamburg, Germany), and they were stored at $-70^{\circ} \mathrm{C}$ until further examination. Care was taken to not irritate the conjunctiva, cornea, or lid margin.

\section{Preparation of single cell suspension}

Collecting the conjunctiva of the two groups within 3 hours using conjunctival polyethersulfone filter membrane (cutting the membrane in half and placing it on the unexposed conjunctiva separately on the superior temporal side and superior nasal side). Then, the filter membranes of two groups were transferred into RPMI1640 cell culture fluid (which included 10\% fetal bovine serum, $100 \mathrm{UI} / \mathrm{ml}$ penicillin, $100 \mathrm{Ul} / \mathrm{ml}$ streptomycin, and $2 \mathrm{mM}$ glutamate). The collected cells were immediately stored at $4^{\circ} \mathrm{C}$ to prevent degradation of the samples. To collect more cells from the membrane, each test tube was stirred 
for 10-15 min; Then, the cell suspension was removed, transferred to a clean test tube and centrifuged $\left(1600 \mathrm{r} / \mathrm{min}, 8 \mathrm{~min}, 4^{\circ} \mathrm{C}\right)$.

\section{Western-blot}

The expression levels of TGF- $\beta 1$, NF-KB and interleukin-17 (IL-17) were detected by western-blot. The single cell suspensions of two groups that were prepared were washed 2 times by $4^{\circ} \mathrm{C}$ precooled phosphate buffer solution, and $400 \mu \mathrm{l}$ cell lysate RIPA was added. Then, the suspensions were cracked on ice for $30 \mathrm{~min}$ and centrifuged for $30 \mathrm{~min}(12 \times 103 \mathrm{r} \cdot \mathrm{min}-1)$. Then, the supernatant of the protein was collected and packed for storage. The sample protein was then subjected to polyacrylamide gel electrophoresis. This experiment was repeated three times.

\section{Flow cytometric}

The supernatant of the cell suspension was removed, and the heavy suspension was placed in $0.3 \mathrm{ml}$ medium. Then, the cells were counted by flow cytometry. The same threshold was used for analysis on a FACS Calibur to avoid cell debris. The same voltage was used for the forward scattering (FSC) and lateral scattering (LSC). Each specimen was analyzed for $60 \mathrm{~s}$.

\section{Enzyme-linked immunosorbent assay (ELISA)}

The IL-I $\beta$, interleukin- 6 (IL-6) and TNF-a levels in tears of subjects were measured using commercial ELISA kits (Quantikine; R\&D Systems, Minneapolis, MN) according to the manufacturer's instructions.

\section{Statistical analysis}

SPSS 17.0 software (SPSS Inc., Chicago, IL, USA) was used to analyze the data. The Mann-Whitney U test and Student's $t$ were used to compare results between groups and Spearman correlation coefficients were calculated for the correlation between levels of inflammatory cytokines and parameters of tear film and ocular surface. $P<0.05$ was considered statistically significant.

\section{Results}

\section{The BUT, SIt and CFS results}

The BUT, SIt and CFS results in the DM group were significantly lower than those in the normal group, and the score of the OSDI in the DM group was significantly higher than that in the normal group. The differences in these parameters between the two groups were statistically significant $(P<0.001, P<$ $0.001, P<0.001$, and $P=0.034$, Table 1).

\section{The conjunctival impression cytology results}

The conjunctival impression cytology results of the two groups were significantly different. In the DM group, the number of conjunctival goblet cells was very small, the number of abnormal bulbar 
conjunctiva was large, and the number of inflammatory cells was large. The conjunctiva were big and sparse, the ratio of nucleus to cytoplasm was increased, binuclear cells and rod-like chromatin cells were found, and a small number of nuclei showed "snake-like" changes (Fig. 1). The number of goblet cells in the conjunctiva of the normal group was more than that in the conjunctiva of the DM group, and few infiltrated inflammatory cells were found in the normal group.

\section{The expression of TGF- $\beta 1$ and NF-KB in the conjunctiva}

TGF- $\beta 1$ in the conjunctiva of the normal group produced a light brown yellow positive reaction, and its positive expression rate was $18 \%$. TGF- $\beta 1$ in the DM group produced a dark brown positive reaction, and its positive expression rate was $81 \%$. NF-KB in the conjunctiva of the normal group produced a brown yellow positive reaction, and its positive expression rate was $21 \%$. NF-KB in the DM group produced a dark brown positive reaction, and its positive expression rate was $77 \%$. Compared with the normal group, the expression levels of TGF- $\beta 1$ and NF-KB in the conjunctiva of the DM group were significantly increased $(P=0.008$ and $P=0.016)$. The TGF- $\beta 1$ level was significantly correlated with the NF-KB level $(r$ $=0.654, P=0.005)$. The results of the correlation between the TGF- $\beta 1$ and NF-KB levels were presented in Figure 2.

\section{The western-blot results}

The western-blot results represented that the expression levels of TGF- $\beta 1, N F-K B$ and IL-17 in the conjunctiva of the normal group were weak, but the expression levels of NF-KB and IL-17 in the DM group were significantly increased. Additionally, the intensity of NF-KB and IL-17 in the DM group was higher than that of b-actin, which served as an internal reference (Fig.3).

\section{Detection of the levels of IL-I $\beta$, IL- 6 and TNF- $a$}

Detection of the levels of IL-I $\beta$, IL- 6 and TNF- $\alpha$ was performed by ELISA. The levels of IL-I $\beta$ and TNF- $\alpha$ in the DM group were significantly higher than those in the normal group $(P<0.001$ and $P=0.023)$ (Fig. 4). The IL-6 level in the DM group was significantly correlated with the BUT $(r=0.50, P=0.02)$, SIt $(r=0.70, P$ $<0.001)$ and goblet cell density $(r=0.46, P=0.04)$. However, the IL-6 level in the normal group was not correlated with the BUT $(r=0.19, P=0.53)$, SIt $(r=0.20, P=0.49)$ or goblet cell density $(r=0.31, P=0.14)$ (Fig. 5).

\section{Flow cytometry results}

Flow cytometry was performed to quantify the CCR4+CD4+, CCR5+CD4+, CCR6+CD4+ and Th-17 cells from the conjunctiva. The percentages of CCR4+CD4+, CCR5+CD4+, and CCR6+CD4+ cells on flow cytometry were $1.0 \pm 0.9 \%, 2.1 \pm 1.7 \%$, and $5.3 \pm 2.4 \%$ in the normal group and $1.1 \pm 0.8 \%, 9.5 \pm 5.3 \%$, and $20.2 \pm 5.7 \%$ in the DM group $(P=0.923, P=0.013$, and $P<0.001$ compared with the normal group) (Fig. $6)$. The number of Th-17 cells in the DM group was significantly higher than that in the normal group $(P<$ 0.001). The first quadrant of the scatter plot included CD4+IL-17+Th cells, the CD4-FITC cell monochromatic in Figure 7C, and the IL-17cell monochromatic in Figure 7D (Fig. 7). 


\section{Discussion}

In recent years, with the increasing number of diabetics, DED caused by diabetes has generated widespread attention[6]. According to the 2017 TFOS DEWS definition of dry eye, [7] "Dry eye is a multifactorial disease of the tears and ocular surface that results in symptoms of discomfort, visual disturbance, and tear film instability with potential damage to the ocular surface. It is accompanied by increased osmolarity of the tear film and inflammation of the ocular surface". As is well-known, the inflammatory reaction plays a prominent role in the pathogenesis of DED; However, there has been a lack of study on the pathogenesis of DED in diabetics. The purpose of this research was to study the mechanism of inflammatory cytokines on ocular surface damage from dry eye in diabetics, to essentially diagnose and treat DED in diabetics and to guide clinical significance.

Recently, an increasing number of scholars thought $[8,9]$ that the immune mechanism, including an abnormal function of both cellular immunity and humoral immunity, plays an important role in type 2 diabetes and its chronic complications. Studies have shown that $[10,11,12]$, when diabetics have immune dysfunction, a personal hyperglycemia condition and oxidative stress could be induced and a large number of oxidative stress products could activate the NF-KB signaling pathway to up-regulate or downregulate the expressions of inflammatory cytokines. In this study, compared to those in the normal group, the positive expression rates of TGF- $\beta 1$ and NF-KB in the conjunctiva of the DM group were significantly increased. The expression of TGF- $\beta 1$ in conjunctiva was positively correlated with the expression of NF$\mathrm{KB}$ in the DM group. We also analyzed the expression levels of TGF- $\beta 1$ and NF-KB and involved in the pathogenesis of DED in diabetes in the conjunctiva by western-blot and the expression level of NF-KB in the DM group was significantly increased. These findings suggested that both TGF- $\beta 1$ and NF-KB might play an important role in regulating immune inflammation of the ocular surface of dry eye in diabetics. It can be inferred that in the pathogenesis of dry eye in diabetics, a large number of NF-KB and TGF- $\beta 1$ was produced when the NF-KB signaling pathway was activated.

In non-stimulated cells, NF-KB dimmers are located in the cytoplasm. Various extracellular stimuli, including TNF- $\alpha$ and IL-I $\beta$, lead to NF-KB activation[13,14] and IL-6 secretion[15]. In this study, we investigated the levels of IL-I $\beta$, IL- 6 and TNF- $\alpha$ in the tears of DM patients. We found that the levels of TNF- $\alpha$ and IL-I $\beta$ were increased significantly in the tears of diabetics complicated with dry eye syndrome compared with normal individuals. However, the IL- 6 level between the two groups were not significantly different. We found that the IL-6 level was significantly correlated with the BUT, SIt and density of conjunctival goblet cells. These results suggested that the IL-6 level is associated with the severity of this disease and correlates with various tear film and ocular surface parameters. IL-I $\beta$, IL- 6 and TNF-a might enhance the ocular surface inflammation by participating in the activation of the NF-KB signaling pathway.

Many studies have indicated that a large number of inflammatory cytokines are activated when the NF$K B$ signaling pathway is activated[16,17]. Chemokines are a kind of cytokines that could be united in the surface of endothelial cells, and they play a role in chemotaxis and activation of inflammatory cells. 
$[18,19]$ After chemokines bind with their receptors, they induce chemotaxis to inflammatory cells, which express corresponding chemokine receptors and recruit a large number of inflammatory factors to participate in the inflammatory reaction. In this study, a significant over expression of CCR5+CD4+ and CCR6+CD4+ was found in conjunctiva compared with normal eyes. These results suggest that chemokines might play an important role in the inflammatory reaction in diabetics with dry eye.

Inflammatory mediators promote the activation of immature an-tigen-presenting cells (APCs) and priming naive $T$ cells in the lymphoid compartment, leading to the expansion of the autoreactive CD4 helper $T$ cell Th17 cell subsets[16]. Studies found that CCR6 induces chemotaxis and the migration of Th-17 cells to participate in the inflammatory reaction[20,21]. In this study, the levels of CCR6+CD4+ and IL-17+CD4+T cells in the conjunctiva of the DM group were higher than those of the normal group. These results suggest that the levels of the chemokine CCR6 and Th17 cells were significantly increased in conjunctiva in those with dry eye and diabetes compared with the normal group and that they might play an important role in the inflammatory reaction.

\section{Conclusions}

DED is significantly more common in diabetics than in normal individuals. The inflammatory cytokines in conjunctiva and tears are significantly different between diabetics with dry eye and normal people. The immune inflammatory reaction and NF-KB signaling pathway might play a vital role in the pathogenesis of dry eye in type 2 diabetic patients. In addition, our studies suggest that the IL- 6 level is associated with the severity of disease and is correlated with ocular surface parameters. By studying the pathogenesis of dry eye in diabetics, we can provide new ideas for the diagnosis and treatment of this disease. This experiment is only a preliminary exploration of the pathogenesis, more experiments needed to further study in diabetics with DED.

\section{Abbreviations}

DM: diabetes mellitus; DED: dry eye disease; NF-kB: nuclear factor-kB;

TGF- $\beta 1$ : transforming growth factor- $\beta 1$; IL-I $\beta$ : interleukin-I $\beta$; TNF- $\alpha$ : tumor necrosis factor-a

SIt: Schirmer test; BUT: tear film breakup time; CFS: corneal fluorecein staining

ADA: American Diabetes Association; HbA1c: glycosylated hemoglobin

FPG: fasting plasma glucose; 2hPG: two hours postprandial blood glucose

OGTT: oral glucose tolerance test; OSDI: ocular surface disease index

PAS: periodic acid-Schiff staining; IL-17: interleukin-17

ELISA: enzyme-linked immunosorbent assay; FSC: forward scattering 
LSC: lateral scattering; IL-6: interleukin-6; APCs: an-tigen-presenting cells

\section{Declarations}

\section{Ethics approval and consent to participate}

The institutional review board at Affiliated Hospital of Yanbian University approved this study, which followed the tenets of the Declaration of Helsinki. Written informed consent was obtained from all patients after the nature and possible consequences of the study were explained.

\section{Consent to publish}

Not applicable.

\section{Availability of data and materials}

The datasets and materials used during the current study are available from the corresponding author on reasonable request.

\section{Competing interests}

The authors declare that they have no competing interests.

\section{Funding}

This study was supported by the National Natural Science Foundation of China (81460091).

\section{Authors' contributions}

$\mathrm{HC}$ took part in the design of the study, and revised the manuscript; ZRL participated in collecting the data and writing the manuscript; NR and LXS was involved in analysis and interpretation of data and revising manuscript; YJL participated in the design of the study and gave final approval of the version to be published. All authors read and approved the final manuscript.

\section{Acknowledgements}

Not applicable.

\section{Publisher's Note}

Springer Nature remains neutral with regard to jurisdictional claims in published maps and institutional affiliations. 


\section{Author details}

a Department of Ophthalmology, Affiliated Hospital of Yanbian University, Yanji Jilin, 133-000, China.

\section{References}

[1] Rathnakumar K, Ramachandran K, Ramesh V, Anebaracy V, Vidhya R, Vinothkumar R and et al.

Prevalence of dry eye disease in type 2 diabetic patients and its association with retinopathy. Int $J$ Pharm Sci Res. 2017;8(10):4298-4304

[2] Fuerst N, Langelier N, Massaro-Giordano M, Pistilli M, Stasi K, Burns $C$ and et al. Tear osmolarity and dry eye symptoms in diabetics. Clin Ophthalmol. 2014;8:507-515

[3] Gao Y, Zhang Y, Ru YS, Wang XW, Yang JZ, Li CH and et al. Ocular surface changes in type $\nabla$ diabetic patients with proliferative diabetic reinopathy. Int J Ophthalmol. 2015;8(2):358-364

[4] Flavio M, Mina MG, Ilaria M, Alessandro L, Stefano B. The Cellular Mechanisms of Dry Eye: from Pathogenesis to Treatment. J Cellular Physiol. 2013;228(12):2253-2256

[5] Aljarousha M, Badarudin NE, Che-Azemin MZ. Comparison of dry eye parameters between diabetics and non-diabetics in district of kuantan, Pahang. Malays J Med Sci. 2016;23(3):72-77

[6] Panahi G, Pasalar P, Zare M, Rizzuto R, Meshkani R. High glucose induces inflammatory responses in HepG2 cells via the oxidative stress-mediated activation of NF-jB, and MAPK pathways in HepG2 cells. Archi Physi Biochem. 2018;124(5):468-474

[7] Craig JP, Nichols KK, Akpek EK, Caffery B, Joo CK, Liu ZG and et al. TFOS DEWS II definition and classification report. Ocul Surf. 2017;15(3):276-283

[8] Sosne G, Qiu P, Christopherson PL, Wheater MK. Wheater MKThymosin beta 4 suppression of corneal NF-kB: A potential anti-inflammatory pathway. Exp Eye Res. 2007;84(4):663-669

[9] Pickup Dphil Frcpath JC. Inflammation and activated innate immunity in the

pathogenesis of type 2 diabetes. Diabetes Care. 2004;27(3):813-823

[10] Chen Y, Zhang L, Yang L, Li M, Li B, Wang WF, Sheng MJ and et al. Decreased PPAR-Y expression in the conjunctiva and increased expression of TNF- $a$ and IL-1 $\beta$ in the conjunctiva and tear fluid of dry eye mice. Mol Med Rep. 2014;9(5):2015-2023

[11] Wei Y, Asbell PA. The core mechanism of dry eye disease is inflammation. Eye \& Contact Lens. 2014;40(4):248-256 
[12] Stevenson W, Chauhan SK, Dana R. Dry eye disease: an immune-mediated ocular surface disorder. Arch Ophthalmol. 2012;130(1):90-100

[13] Chauhan SK, Dana R. Role of Th17 cells in the immunopathogenesis of dry eye disease. Mucosal Immunol. 2009;2(4):375-376

[14] Barabino S, Chen Y, Chauhan S, Dana R. Ocular surface immunity: homeostatic mechanisms and their disruption in dry eye disease. Prog Retin Eye Res. 2012;31(3):271-285

[15] Choi W, Li ZR, Oh HJ, Lee SH, Park SH, You IC and et al. Expression of CCR5 and Its Ligands CCL3, -4, and -5 in the Tear Film and Ocular Surface of Patients with Dry Eye Disease. Curr Eye Res. 2012;37(1):1217

[16] Pflugfelder SC, Corrales RM, Paiva CS. T helper cytokines in dry eye disease. Exp Eye Res. 2013;117:118-125

[17] Kolb H, Mandrup P. An immune origin of type 2 diabetes? Diabetologia. 2015;48(6):1038-1050

[18] Donath MY, Shoelson SE. Type 2 diabetes as an inflammatory disease. Nat Rev Immunol. 2011;11(2):98-107

[19] Coursey TG, Gandhi NB, Volpe EA, Pflugfelder SC, Paiva CS. Chemokine receptors CCR6 and CXCR3 are necessary for $\mathrm{CD} 4(+) \mathrm{T}$ cell mediated ocular surface disease in experimental dry eye disease. Plos One. 2013;8(11):e78508. Doi:10.1371/journal.pone.0078508

[20] Hessen M, Akpek EK. Dry eye: an inflammatory ocular disease. J Ophthalmic Vis Res. 2014;9(2):240250.

[21] Dandona P, Aljada A, Bandyopadhyay A. Inflammation: the link between insulin resistance, obesity and diabetes. Trends Immunol. 2004;25(1):4-7

\section{Tables}

Table 1. General data of the normal and DM group. 


\begin{tabular}{llll}
\hline Parameters & Normal Group & DM Group & $P$ Value \\
\hline Number & 117 & 102 & 0.852 \\
OSDI & $9.52 \pm 8.67$ & $26.23 \pm 9.65$ & $<0.001$ \\
BUT/s & $12.17 \pm 2.31$ & $3.64 \pm 1.23$ & $<0.001$ \\
SIT/mm & $15.21 \pm 3.25$ & $7.16 \pm 1.09$ & $<0.001$ \\
CFS & $3.56 \pm 1.93$ & $2.41 \pm 2.13$ & 0.034 \\
\hline
\end{tabular}

\section{Figures}
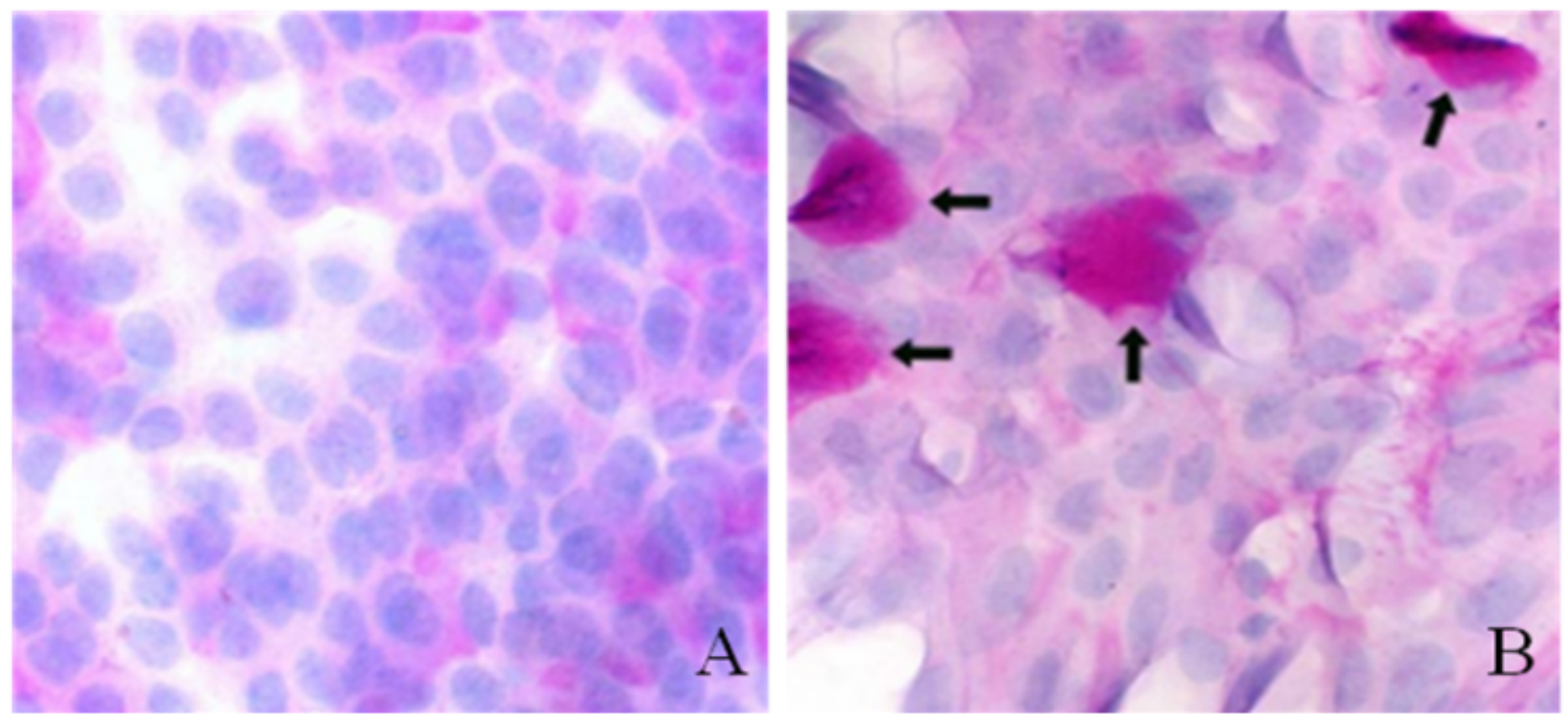

\section{Figure 1}

The results of the conjunctival impression cytology in the two groups (PAS x400). A: the normal group. B: the DM group. ( $\uparrow$ : indicating positive reaction cells). 

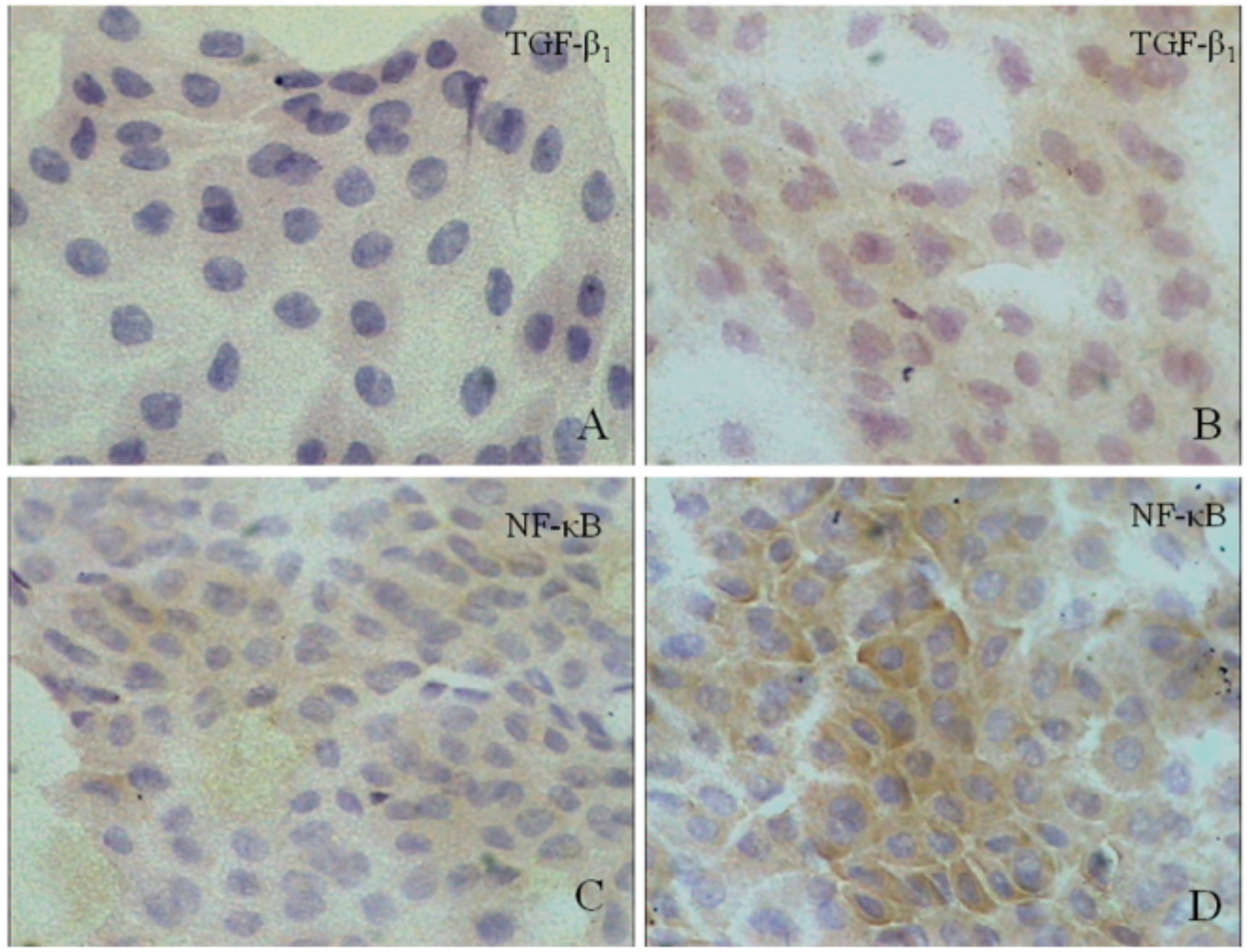

Figure 2

The expressions of TGF- $\beta 1$ and NF-KB in the conjunctival epithelial cells of the normal group $(\mathrm{A}, \mathrm{C})$ and the DM group(B,D) (Immunohistochemical Staining x400). 


\section{Normal DM}

TGF- $\beta_{1}$

$\mathbf{N F}-\mathbf{k B}$

IL-17

$\beta$-actin
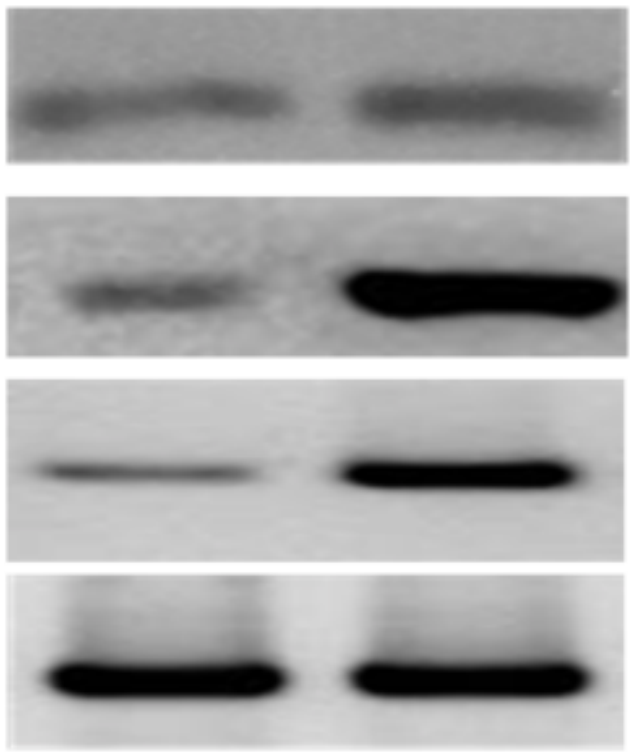

\section{Figure 3}

TGF- $\beta 1, N F-K B$ and IL-17 expression intensities in the conjunctival epithelial cells of the two groups.
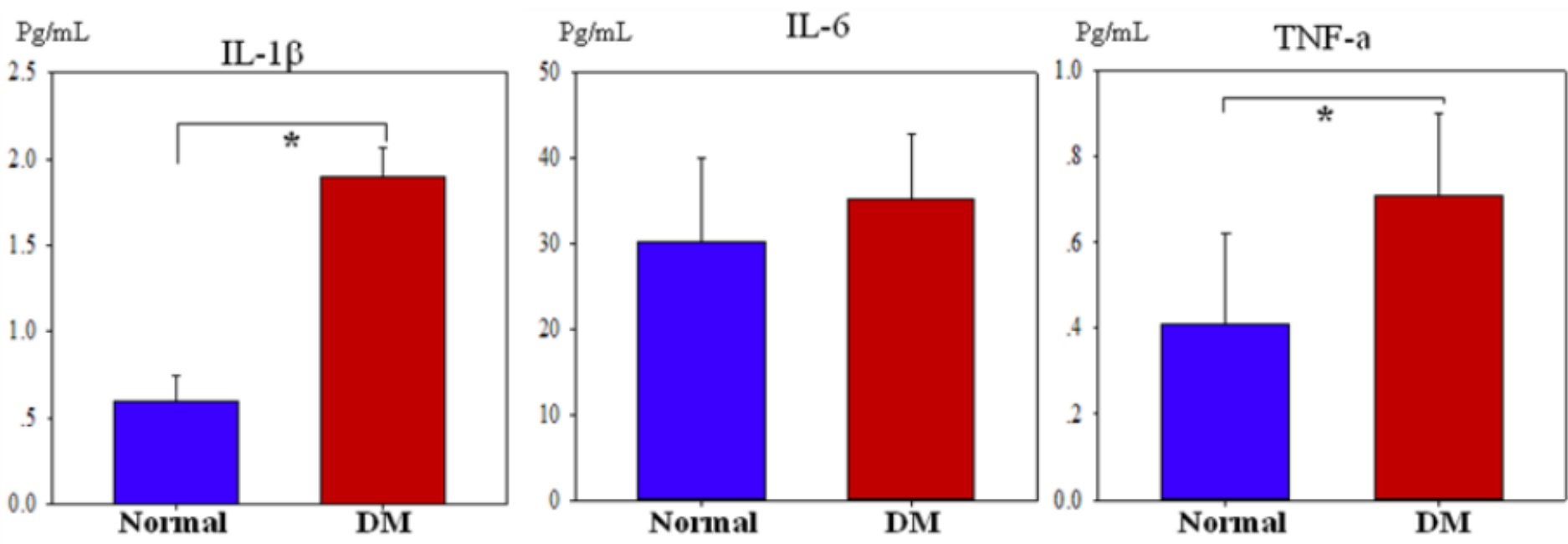

Figure 4

IL-I $\beta$, IL- 6 and TNF- $\alpha$ levels in the tears of the normal subjects and DM subjects. ( *: compared with the normal group, $\mathrm{P}<0.05$ ). 


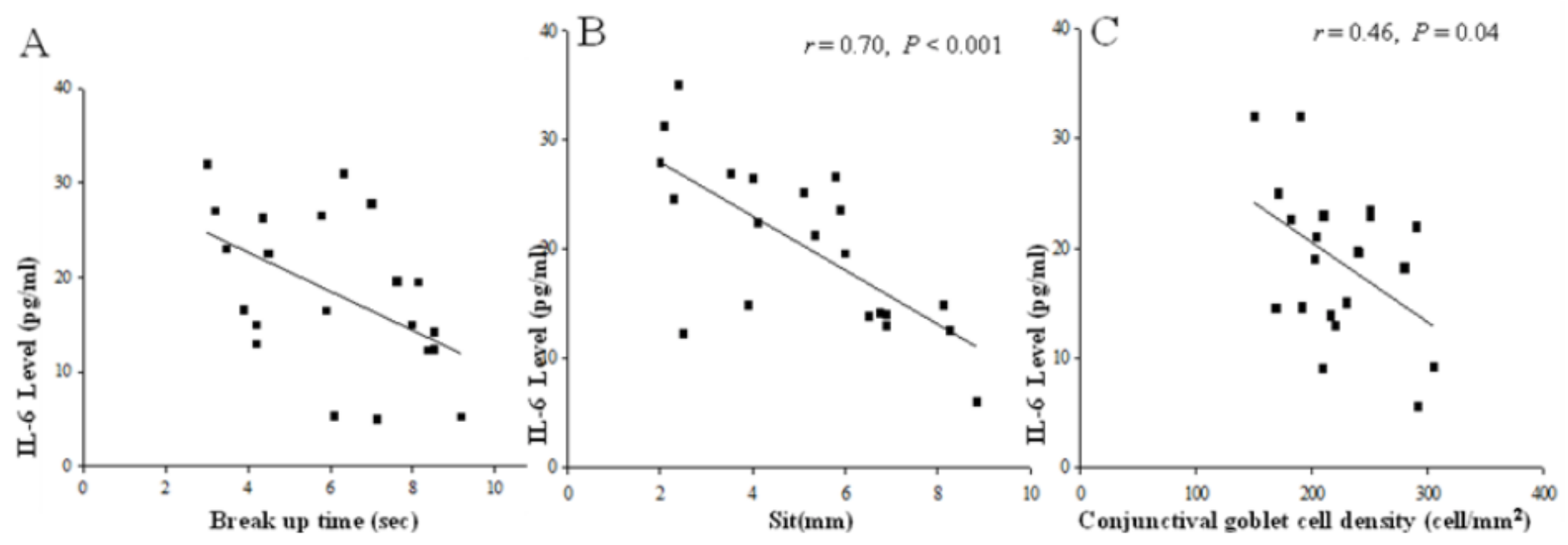

Figure 5

Correlation between the IL-6 level in tears and tear film and the ocular surface parameters, including the BUT (A), Schirmer test (B) and conjunctival goblet cell density (C). Figure 6 . Flow cytometry showing CCR4+CD4+ (A), CCR5+CD4+ (B), and CCR6+CD4+ (C) cells in the conjunctiva of the normal group and DM group. 

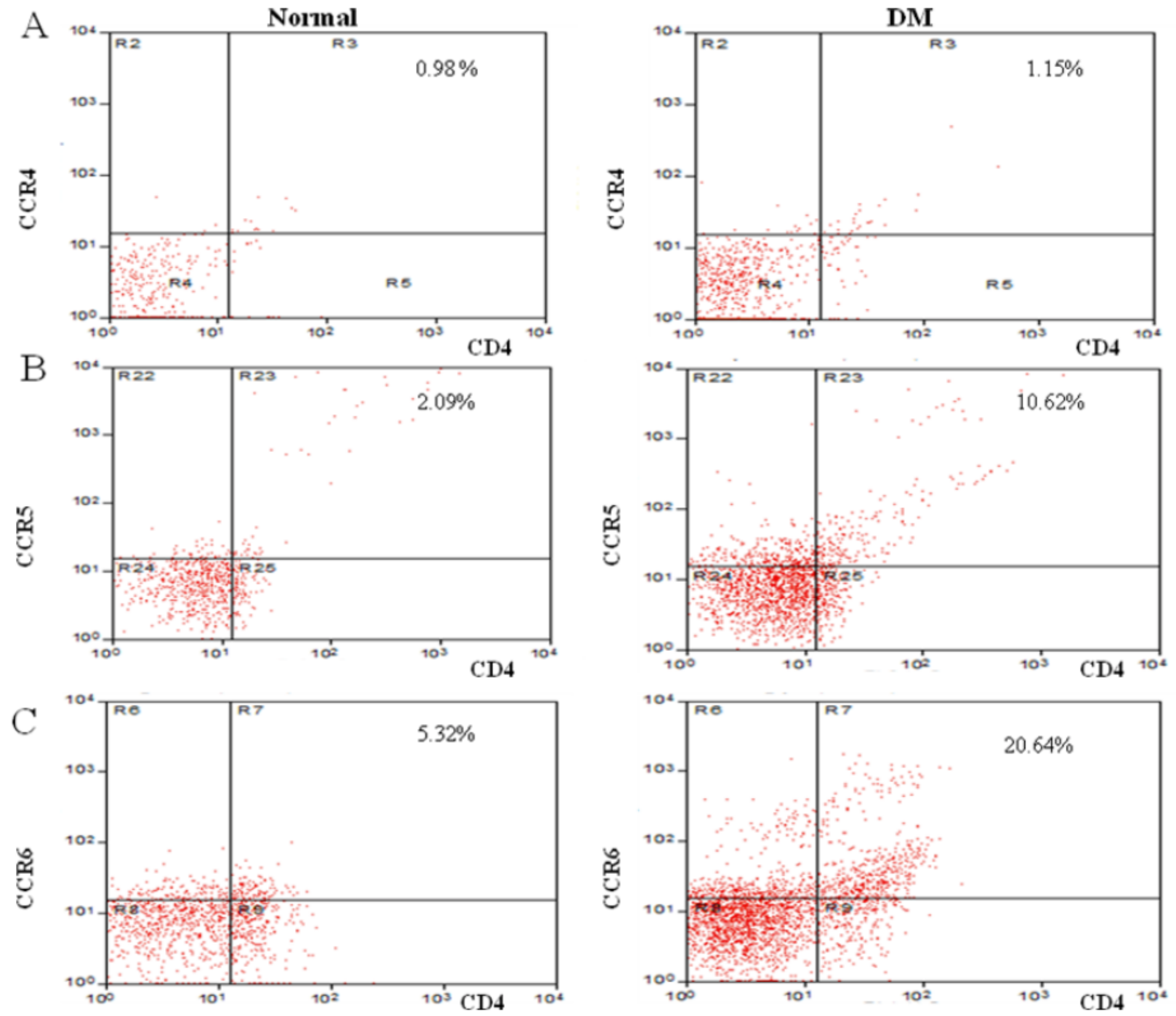

Figure 6

Flow cytometry showing CCR4+CD4+ (A), CCR5+CD4+ (B), and CCR6+CD4+ (C) cells in the conjunctiva of the normal group and DM group. 

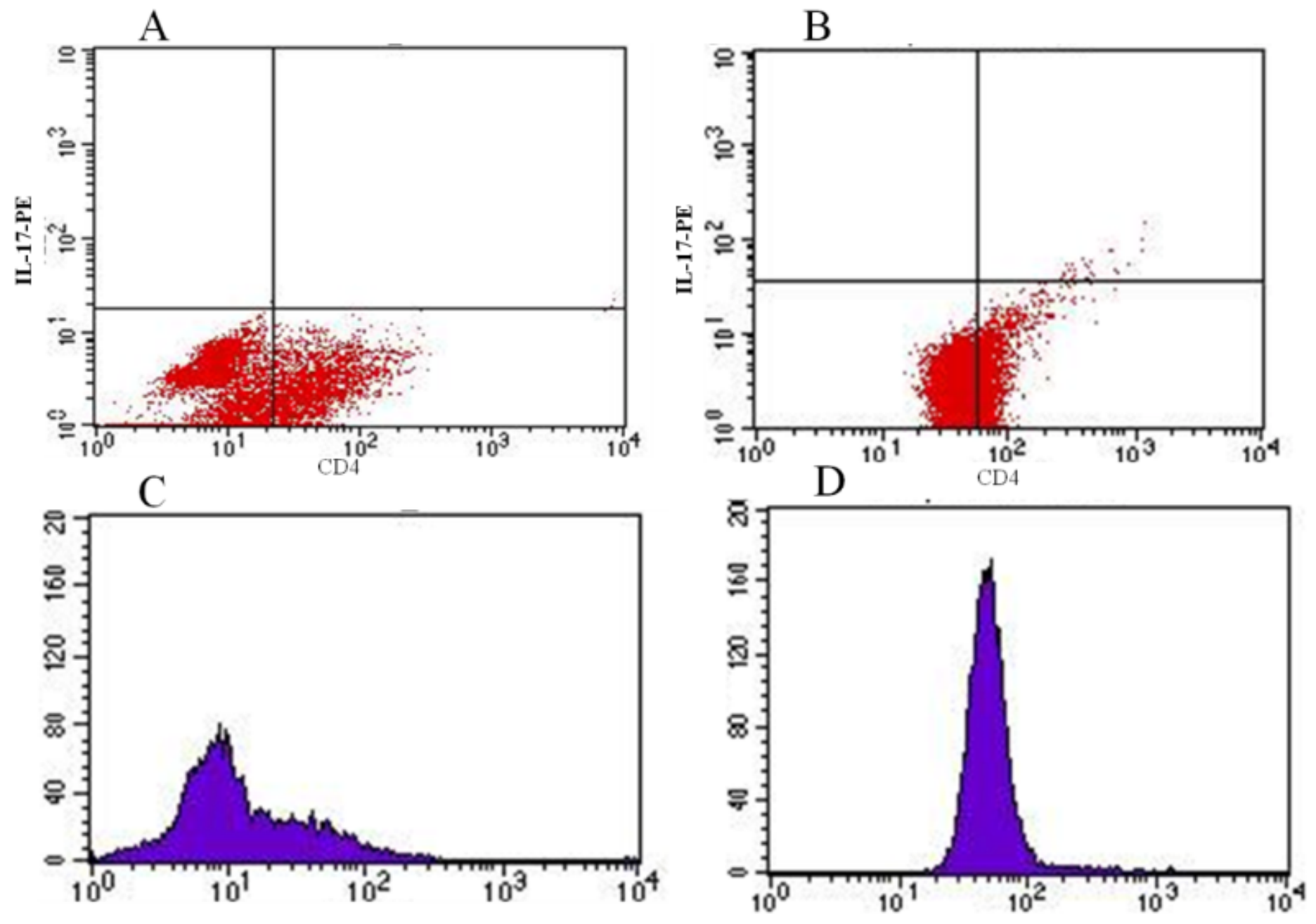

Figure 7

Flow cytometry showing the staining of Th-17 cells in the tears of the normal group (A) and DM group (B) the first quadrant was a CD4+IL-17+Th cell; C: CD4-FITC single-staining; D: IL-17 single-staining. 